\title{
Aa. Vv., Histoire et Roman
}

\section{Maria Colombo Timelli}

\section{(2) OpenEdition}

\section{Journals}

\section{Édition électronique}

URL : http://journals.openedition.org/studifrancesi/29911

DOI : 10.4000/studifrancesi.29911

ISSN : 2427-5856

\section{Éditeur}

Rosenberg \& Sellier

\section{Édition imprimée}

Date de publication : 1 avril 2006

Pagination : 124-125

ISSN : 0039-2944

\section{Référence électronique}

Maria Colombo Timelli, «Aa. Vv., Histoire et Roman», Studi Francesi [En ligne], 148 (XLX | I) | 2006, mis en ligne le 30 novembre 2015, consulté le 19 avril 2021. URL : http://journals.openedition.org/ studifrancesi/29911 ; DOI : https://doi.org/10.4000/studifrancesi.29911

\section{Ce document a été généré automatiquement le 19 avril 2021.}

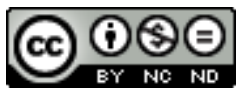

Studi Francesi è distribuita con Licenza Creative Commons Attribuzione - Non commerciale - Non opere derivate 4.0 Internazionale. 


\title{
Aa. Vv., Histoire et Roman
}

\author{
Maria Colombo Timelli
}

\section{RÉFÉRENCE}

Histoire et Roman, « Bien dire et bien aprandre. Revue de Médiévistique », 22, 2004.

AIMÉ PETIT ('Estoire' et 'romanz' dans le 'Roman de Thèbes', pp. 11-21) analyse le sens des mots 'estoire' et 'romanz' dans les différents manuscrits du Roman de Thèbes. C'est dans le ms. A (version longue) que l'on relève le plus grand nombre de mentions d'estoire', pour désigner la source écrite de l'œuvre. Quant à 'romanz', il n'apparaît qu'une fois dans la version longue, avec le sens de 'transposition en langue vulgaire'. D'autre part, Aimé Petit constate dans Thèbes la coexistence de l'histoire antique et de l'histoire du XII ${ }^{e}$ siècle, ce qui crée des effets sensibles d'anachronisme et d'hybridité: le résultat en est un monde poétique qui accueille histoire et fiction romanesque.

EMMANUÈLE BAUMGARTNER ( $\mathrm{Du}$ 'roman' à l'histoire: le motif de la bataille rangée chez Wace et Benoît, pp. 23-37) compare les récits de la bataille d'Hastings dans La geste des Bretuns et dans l'Estoire des dus normanz. Elle relève la précision de Wace, au service de l'évocation de la réalité historique, et la tonalité toute différente par laquelle Benoît de Sainte Maure vise à émouvoir son public et à lui offrir plutôt une leçon de morale. Aux deux extrêmes, cependant, les deux œuvres doivent bien être rangées sous la même étiquette d'estoire', qu'elles se donnent pour se différencier de la 'fable'.

3 MARIE-GeneVIÈVE GROSSEL (L'utilisation du 'Roman d'Alexandre' dans l'Historia Orientalis' de Jacques de Vitry, pp. 53-65). Dans son Historia Orientalis (1221), Jacques de Vitry cite à plusieurs reprises Alexandre le Grand. M.-G. Grossel reconnait la source de certains passages dans le Roman d'Alexandre (surtout la description de 'mirabilia' et d'animaux fantastiques ou réels). Le roi de Macédoine subit cependant une dégradation dans l'Historia, en tant que figure exemplaire des réprouvés auxquels a essentiellement manqué la conscience de leur 'petitesse'.

DOMINIQUE BOUTET (Entre historiographie et roman épique: le 'Myreur des Histors' de Jean d'Outremeuse, pp. 67-78). Chronique universelle relatant l'histoire du monde depuis le 
Déluge jusqu'au XIV ${ }^{\mathrm{e}}$ siècle, le Myreur des Histors introduit, dans un cadre historiographique, des personnages, éléments et motifs provenant de la tradition épique et romanesque. Plutôt que d'une confusion involontaire entre fiction et vérité historique, ce procédé témoigne chez Jean d'Outremeuse d'une volonté délibérée de manipuler ses sources.

FRANÇOISE VIELLIARD ('Ci dist li conte et la sainte Escripture le tesmoigne'. Histoire et fiction dans le manuscrit Bodmer 147, pp. 79-90). Le ms. Bodmer 147 transmet une compilation qui associe à l'Estoire del Saint Graal, au Merlin et à la Suite-Vulgate, un nombre important de textes bibliques et d'histoire profane (Roman de Troie, Faits des Romains). Le compilateur combine les données de l'histoire biblique, de l'histoire du Graal et de l'histoire païenne, et associe 'conte' et 'Escriture sainte' dans les formules de transition à une interpolation.

CATHERINE CROIZY-NAQUET (De la tentation du roman au triomphe de l'histoire: César dans les 'Faits des Romains' et le 'Romuleon', pp. 91-102). Au-delà des sources communes (Suétone surtout), l'auteur anonyme des Faits des Romains et Sébastien Mamerot offrent deux portraits différents de l'empereur romain: le César des Faits est un personnage romanesque dont on connaît et la psychologie et les aventures; celui du Romuleon est un héros conquérant, exemplaire, en totale empathie avec l'histoire de Rome.

7 Selon JEAN-GUY GOUTTEBROZE (Quand l'histoire relance la création romanesque et la légende. Les merveilles de Glastonbury, pp. 105-118), la découverte de la sépulture d'Arthur et Guenièvre dans le cimetière de l'abbaye de Glastonbury en 1191 a relancé l'écriture de la légende arthurienne en quête d'un statut historique. C'est alors le Perlesvaus qui se conformerait le plus complètement à l'actualisation permise par cette découverte.

GÉRARD GROS (Le fin mot sur Pompée: étude littéraire de l'épisode de Foucaire, dans l'Estoire del Saint Graal' § 303 à 318, pp. 119-136). Dans le fragment narratif étudié ici, Pompée débarrasse la Méditerranée du pirate Foucaire: l'analyse prend en compte le lieu narratif et géographique, les protagonistes, l'inclusion de la légende dans l'Histoire et dans l'Estoire, l'interprétation de l'épisode.

Le même passage est utilisé par MIREILLE SÉGUY (Vestiges historiques et mémoire romanesque dans l'Estoire del Saint Graal', pp. 137-152), avec le récit des aventures d'Hyppocrate, pour montrer la façon dont l'auteur de l'Estoire invente et dispose des 'vestiges' (sites historiques, ruines ou monuments) afin d'authentifier son œuvre, et surtout d'imposer son texte comme un récit de commencement et de fondation, malgré sa composition tardive (après l'ensemble du cycle du Graal).

10 JACQUES CHOCHEYRAS (Roman et histoire: trois lieux historiques du 'Tristan' de Béroul: le 'cellier' d'Orri, la Table Ronde d'Isneldone', 'Saint Lubin', pp. 153-166). Il s'agit de l'identification hypothétique des troix lieux énumérés dans le titre avec des sites historiquement documentés. Cette reconnaissance contribuerait à une meilleure compréhension du roman de Béroul.

11 JEAN-MARC PASTRÉ (Histoire et mythe dans les romans de Tristan au Moyen Âge, pp. 167-177) étudie les références antiques dans les romans de Thomas de Bretagne et de Gottfried de Strasbourg.

12 MAGALI JANET (Les scènes de cannibalisme aux abords d'Antioche dans les récits de la première croisade: des chroniques à la chanson de croisade, pp. 179-191) vérifie le traitement d'un épisode historique - le cannibalisme de pénurie constaté aux abords d'Antioche en 1098 - dans un corpus différencié de textes: onze chroniques de la première croisade, la 
Chanson d'Antioche et le Chevalier au Cygne et Godefroy de Bouillon, afin de mesurer le poids exercé par le genre littéraire sur la version proposée. Elle constate alors que les chroniques se distinguent par la prise de position du narrateur et par la brièveté qui caractérise cet épisode; en revanche, dans les chansons de croisade les scènes de cannibalisme peuvent être développées grâce à l'amplification (procédé proprement épique) et marquées par un registre tantôt dramatique tantôt comique. ROBERT BAUDRY (Les premiers pas d'Arthur ou: Dossier Arthur, pp. 193-206) réunit une vingtaine de textes gallois et latins (chroniques et vies de saints composés avant l'Historia regum Britanniae de Geoffroy de Monmouth) évoquant un 'Arthur' historique, peut-être source d'inspiration pour le 'roi Arthur' protagoniste d'une si riche littérature. 